\title{
Diversidade de Processos Argumentativos e a Construção de Cultura Favorável à Argumentação em duas Salas de Aula de Ciências
}

Diversity of Argumentative Processes and the Construction of a Culture of Argumentation in two Science Classrooms

Ana Paula Souto Silva Teles, Danusa Munford

Palavras-chave Resumo O presente estudo busca compreender aspectos da construção

Processos de uma cultura de sala de aula favorável à argumentação por meio do Argumentativos; contraste entre processos argumentativos em duas turmas do Ensino Cultura de salas de Fundamental. Utilizamos ferramentas da etnografia interacional e aula de Ciências; adaptamos aspectos da teoria da argumentação Pragma-dialética.

Teoria da Conduzimos observação participante com registro em notas de campo e argumentação em vídeo. Os resultados evidenciaram que a construção de uma cultura Pragma-dialética. de sala de aula favorável à argumentação ocorre ao longo do tempo e dos eventos, por de meio de processos argumentativos diversos. Em ambas as turmas, as formas como professores interagiram discursivamente com estudantes contribuíram para promover a diferença de opinião e, consequentemente, apoiar uma cultura de argumentação. As formas de participação dos(as) estudantes também contribuíram para a variação na argumentação, pois houve tanto com o(a) professor(a) quanto entre pares. O estudo tem potencial para contribuir para a prática pedagógica e para a formação de professores e para uma melhor compreensão da diversidade de processos argumentativos.

Submetido em 11 de novembro de 2020 Aceito para publicação em 09 de março de 2020

Publicado em 28 de julho de 2021 
Keywords Abstract This study aims to understand aspects of the construction Argumentation of a classroom culture that foster argumentation by contrasting

Processes; argumentative processes in two different middle-school classrooms.

Science classroom We adopted tools from interactional ethnography, and we adapted culture; elements of the Theory of Argumentation Pragma-Dialectics. We

Pragma-Dialectics conducted participant observations with records in field notes theory of and video. The results evidenced that the construction of a culture argumentation. that foster argumentation occurs over time and it involves diverse argumentative processes. In both classrooms we observed that the forms that teachers interacted with students contributed to promote differences of opinion, and, hence, they supported a culture of argumentation. Students participation forms also contributed to the variation in argumentation because they interacted with the teacher, as well as, with their peers. The study has potential to contribute to teachers' practice and teacher education, as well as to advance our understandings about the diversity of argumentation processes.

\section{Introdução}

A argumentação tem um importante papel na aprendizagem (por exemplo exemplo, Billig, 1987; Schwarz, 2009) e, especificamente na Educação em Ciências (por exemplo exemplo, Berland \& Reiser, 2011; Henderson, McNeill, González-Howard, Close, \& Evans, 2018), pois pode contribuir, dentre outros, para o desenvolvimento conceitual, epistêmico e social dos(as) estudantes (por exemplo exemplo, Duschl, 2008).

Contudo, há uma série de desafios para que a argumentação esteja presente na Ciência escolar. Um deles é mudar a cultura da sala de aula de modo que se torne favorável à argumentação (Henderson et al., 2018). Investigar a argumentação sob essa perspectiva da cultura de sala de aula possibilita o diálogo com a ampla e consistente produção sobre a temática, mas também traz novas questões e novos desafios. No presente estudo, inicialmente fazemos uma breve reflexão sobre essa noção de "cultura favorável à argumentação" e fazemos um levantamento de aspectos característicos de uma cultura, por meio do diálogo com a literatura. Esses aspectos orientam nossas análises, fundamentadas em elementos da Etnografia em Educação e da teoria da argumentação Pragma-dialética, perspectivas teórico-metodológicas que buscam dialogar com a noção de cultura e de discurso como ação. Nesse sentido, buscamos adotar uma perspectiva mais descritiva do que normativa, entendendo que essa "descrição" não implica na ausência de busca por explicações para os fenômenos ou de teorização. Tal distinção é utilizada para se demarcar a centralidade da perspectiva dos participantes para compreensão desses fenômenos (Kelly, 2005).

No presente estudo, temos como objetivo compreender aspectos da construção de uma cultura de sala de aula favorável à argumentação por meio do contraste entre processos argumentativos em duas salas de aula do Ensino Fundamental. Nesse sentido, 
nossas questões de pesquisa são: Em que aspectos os processos argumentativos em uma turma do $8^{\circ}$ ano do ensino regular e em uma turma da EJA se assemelham e se diferenciam? Como processos argumentativos das duas turmas estão relacionados à construção de uma cultura de sala de aula favorável à argumentação?

\section{Aspectos da Cultura de sala de aula favorável à Argumentação}

Henderson e colaboradores (2018) dão destaque à centralidade da mudança da cultura de sala de aula para a ocorrência da argumentação. Sandoval et al. (2019), apontam que a cultura para a argumentação corresponde "a um contexto onde as normas e práticas de argumentação se desenvolvem para atender a objetivos coletivos" (Sandoval et al., 2019, p. 16, tradução nossa ${ }^{1}$ ). A partir dessa definição, podemos perceber que a argumentação é entendida como prática cultural em vez de habilidade, e que o foco está no grupo, não no indivíduo. Essas práticas são "modos de falar e agir de membros da comunidade de acordo com normas compartilhadas vinculadas a papéis específicos" (Sandoval et al., 2019, p. 2, tradução nossa ${ }^{2}$ ).

Para delimitar aspectos centrais de uma cultura favorável à argumentação buscamos estabelecer um diálogo mais amplo com a literatura. Henderson e colaboradores (2018) e Sandoval e colaboradores (2019), falam explicitamente sobre cultura da argumentação na Educação em Ciências. Porém, outras pesquisas mesmo sem investigarem a argumentação sob a perspectiva de cultura, trazem importantes contribuições no sentido de possibilitarem a caracterização de aspectos dessa cultura.

O primeiro aspecto de uma cultura de sala de aula favorável à argumentação envolve dúvidas e incertezas. Segundo Henderson e colaboradores (2018), a construção desse tipo de cultura de sala de aula está relacionada a mudanças nas epistemologias da Ciência de docentes e estudantes. Nesse sentido, esses autores sugerem a necessidade de o conhecimento científico ser visto como provisório, aberto à dúvida e à incerteza. Dessa forma, quando estudantes entendem o conhecimento científico como provisório se sentem mais confortáveis para defender seus pontos de vista caso sejam opostos aos conhecimentos científicos.

El-Hani e Mortimer (2007), por exemplo, justificam essa existência de pontos de vista opostos aos conhecimentos científicos a partir da diversidade cultural e linguística dos(as) estudantes, que, quando presentes em salas de aula, geram uma constante tensão, visível ou não, entre diferentes tipos de conhecimento. Nesse sentido, Henderson e colaboradores (2018) sugerem que uma cultura da sala de aula favorável à incerteza e dúvida cria condições para tornar visíveis as epistemologias dos(as) estudantes e, consequentemente, essas diferenças entre os conhecimentos.

O surgimento e resolução de desacordos também são sugeridos por Sandoval e colaboradores (2019) como aspectos importantes para uma cultura favorável à

1 "a context where norms and practices of argumentation develop to meet collective goals." (Sandoval et al., 2019, p. 16).

2 "ways of talking and acting that are enacted by community members according to shared norms attached to specific roles." (Sandoval et al., 2019, p. 2). 
argumentação. Nesse sentido, esses autores sugerem que os(as) estudantes precisam estar engajados(as) com recursos materiais que podem ser usados para gerar e resolver os desacordos. Contudo, em nossas pesquisas observamos que os desacordos também podem surgir nas interações discursivas sem necessariamente haver recursos materiais envolvidos (Munford \& Teles, 2013; Munford \& Teles, 2015).

Sandoval e colaboradores (2019) também apresentaram evidências de que as crianças discordavam naturalmente sobre aspectos conceituais e metodológicos relacionados ao que estavam estudando. Portanto, análises de quando, como e por quem são gerados os desacordos e dos processos de resolução podem contribuir para melhor compreender a construção de uma cultura favorável à argumentação.

O segundo aspecto de uma cultura de sala de aula favorável à argumentação envolve críticas e avaliação. Henderson e colaboradores (2018) sugerem a necessidade de dar mais ênfase à crítica de argumentos, pois existe uma ênfase exagerada na construção de argumentos e a argumentação científica não se restringe a um exercício de construção.

González-Howard e McNeill (2020) apoiam esses autores ao defenderem a centralidade da crítica para a construção, avaliação e revisão do conhecimento durante a argumentação. Segundo essas autoras, a crítica, enquanto prática científica, possibilita a distribuição da agência epistêmica e abrange muitos tipos de interações dialógicas que contribuem para a construção coletiva de significados. Por exemplo, avaliação de evidências e do raciocínio que os colegas apresentam; perguntas uns aos outros; esclarecimento de questões; críticas e debates sobre a força dos argumentos; revisão de argumentos. Essas autoras também sugerem que as interações entre os(as) estudantes relacionados à crítica podem variar, pois são diversas as formas de participação dos(as) estudantes nesses tipos de interações dialógicas.

Apesar de Sandoval e colaboradores (2019) não usarem os termos "crítica" e "avaliação" em seu estudo, sugerem que mudanças na cultura de sala de aula levam à responsabilidade social, pois os critérios e padrões para o trabalho são gerados e refinados pelos(as) estudantes. Nesse sentido, podemos interpretar esses "critérios e padrões" como formas de avaliar/criticar os argumentos e outras etapas do trabalho. Esses autores também sugerem que esses mecanismos de responsabilidade e a localização da autoridade (a quem os e as estudantes se dirigem) são formas de manifestação da distribuição da agência epistêmica. Dessa forma, podemos dizer que tanto para González-Howard e McNeill (2020) quanto para Sandoval e colaboradores (2019) as análises da distribuição da agência epistêmica estão relacionadas às práticas de crítica e de avaliação em sala de aula.

Outro aspecto que favorece a ocorrência de crítica e avaliação são os contraargumentos, entendidos como objeções a um ponto de vista ou argumento (Leitão, 2000). Para Leitão (2000), os contra-argumentos podem surgir de diferentes formas. Por exemplo, mudando o foco da argumentação (ao oferecer suporte a um outro lado da questão); e buscando descartar um elemento do argumento em questão (apenas 
negando-o ou questionando a verdade de uma afirmação). Essa autora também sugere que há diferentes respostas aos contra-argumentos. Por exemplo, as objeções podem ser aceitas, integradas (adaptação do argumento à crítica, qualificando-o ou fornecendo mais evidências), localizadas (aceitação parcial) ou rejeitadas (rejeição a oposição ao seu argumento atacando a própria declaração de oposição).

Para que essas práticas de crítica e avaliação façam parte da cultura de sala de aula é necessário que os(as) estudantes entendam que os objetos de crítica são as ideias, não as pessoas (Henderson et al., 2018); que reconheçam o contexto como argumentativo e favorável à crítica (ex. Berland \& Hammer, 2012; González-Howard \& McNeill, 2020); e reconheçam a necessidade de ouvir os outros e de se posicionar (GonzálezHoward \& McNeill, 2020).

O terceiro aspecto da construção de uma cultura de sala de aula favorável à argumentação é a dimensão temporal e processual. Larraín e Freire (2011) apontam que a aprendizagem de argumentação científica ocorre de forma processual. Na perspectiva dessas autoras, a capacidade de argumentar, principalmente considerandose a capacidade de apresentar ideias opostas, pode ser investigada mesmo em crianças de tenra idade. Dessa forma, a capacidade de compreender a estrutura de argumentos seria a parte final desse processo e seria facilitado se, desde tenra idade, as crianças fossem estimuladas a defender seus pontos de vista e a apresentar críticas às ideias opostas.

Essa consideração de que mudanças na cultura ocorrem ao longo do tempo e de eventos também pode ajudar a explicar os resultados de estudos citados por Berland e Reiser (2011), que sugerem que mudanças nas práticas das comunidades de sala de aula não são triviais. Essa não trivialidade na transformação de práticas pode ser devido ao fato de que essas mudanças envolvem, segundo a Etnografia em Educação, renegociar as normas e expectativas construídas no grupo ao longo do tempo e dos eventos, exigindo mudanças nas formas de interagir entre os membros da comunidade (Green et al., 2005).

Essa dimensão temporal pode explicar também mudanças nas formas de participação dos(as) estudantes quando não há alterações nas questões colocadas pelos(as) professores(as) (McNeill \& Pimentel, 2010) ou na forma como os(as) estudantes interpretam os contextos instrucionais (Berland \& Hammer, 2012). No estudo de McNeill e Pimentel (2010), por exemplo, o principal fator que contribuiu para aumentar a interação entre os(as) estudantes e a presença de contra-argumentos foi os(as) professores(as) colocarem questões mais abertas. Enquanto que no estudo de Berland e Hammer (2012), o principal fator que pareceu justificar essas mudanças foi o fato de os(as) estudantes reconhecerem os contextos instrucionais como argumentativos.

Portanto, quando considera-se um período maior para as análises, é possível caracterizar como os papéis, que são construídos situacionalmente nas ações e interações, variam e mudam ao longo do tempo/em diferentes situações; e como as maneiras pelas quais o conhecimento e os textos gerados em um evento se vinculam e se tornam um recurso para as ações dos membros em eventos subsequentes. Além disso, o papel do(a) docente no processo e as mudanças nas formas de participação dos(as) estudantes 
podem ser melhor compreendidos.

O quarto aspecto envolvido na construção de uma cultura de sala de aula favorável à argumentação é a diversidade. Há várias pesquisas que não investigaram a argumentação a partir da perspectiva de cultura, mas trazem evidências de que existem formas distintas de argumentar e que conhecer essas diferenças pode favorecer a inclusão de grupos minoritários na aprendizagem de Ciências. Nesse sentido, inferimos que a construção de uma cultura favorável à argumentação pode ocorrer de diferentes formas.

No estudo de Berland e Reiser (2011), por exemplo, elementos-chave do discurso da argumentação científica possibilitaram caracterizar o movimento entre objetivos de persuasão e de compreensão ("sense-making"). Entretanto, o engajamento em persuasão e em "sense-making" não foi o mesmo nas duas turmas, configurando diferentes formas de argumentação científica.

Paralelamente, Baker (2015), destacou a diversidade de formas de argumentar ao sugerir a existência de uma variedade de diálogos que envolvem compartilhamento de argumentos que são importantes para a Educação, mas não são conflitos plenos declarados.

Já no estudo de Gonzálex-Howard e McNeill (2020), as autoras apresentam evidências de que existem várias formas de criticar em situações argumentativas. Algumas dessas formas podem não ser reconhecidas pela comunidade de sala de aula ou não estar alinhadas às formas dominantes de conhecer e explicar o mundo. Dessa forma, essas autoras sugerem a necessidade de conhecer, valorizar as diferentes formas de fazer ciência, principalmente, de argumentar na sala de aula.

Essa necessidade de conhecer outras formas de argumentar, principalmente, a de grupos minoritários torna-se cada vez mais reconhecida no campo de pesquisa face à diversidade cultural e linguística dos(as) estudantes e da importância de garantir a sua participação (por exemplo exemplo, González-Howard \& McNeill, 2020, Henderson et al., 2018). Nesse sentido, análises das interações discursivas a partir de uma perspectiva cultural podem, portanto, contribuir para que essa diversidade se torne visível.

O quinto aspecto relacionado à construção de uma cultura de sala de aula favorável à argumentação é a dimensão social e coletiva. Conforme mencionamos anteriormente, o grupo/coletivo é central para a definição de cultura apresentada por Sandoval e colaboradores (2019). Nesse sentido, Rudsberg et al. (2017), mesmo não tendo como foco a cultura, evidenciam como por meio das interações discursivas, estudantes influenciam-se mutuamente, contribuindo com a argumentação e a construção coletiva de conhecimentos. Do mesmo modo, os conhecimentos construídos pelo grupo influenciam a argumentação individual de cada estudante.

Sandoval e colaboradores (2019), além de reconhecer que a construção de significados é inerentemente coletiva, sugerem que as práticas de argumentação precisam estar situadas em atividades mais amplas de produção do conhecimento e os(as) estudantes precisam perceber razões para argumentar. Nessa perspectiva, essas práticas surgem naturalmente e visam alcançar um consenso sobre objetivos 
específicos compartilhados coletivamente. Além disso, o(a) professor(a) apresenta papel determinante para ajudar os(as) estudantes a manterem o foco nas principais questões epistêmicas a serem resolvidas e a se envolverem com as ideias uns dos outros de forma produtiva e com responsabilidade.

Outros estudos que não analisam interações da sala de aula a partir de uma perspectiva cultural, trazem evidências da centralidade dessa dimensão social. No estudo de Berland e Hammer (2012), por exemplo, o engajamento na argumentação foi favorecido quando estudantes reconheceram o contexto como argumentativo e foram estimulados pelos(as) docentes a desafiarem as ideias uns dos outros. No caso de McNeill e Pimentel (2010), questões mais abertas da professora favoreceram maior interação entre estudantes, que compartilharam mais suas ideias, esclarecendo qual era sua forma de raciocinar e conectando ideias com os colegas.

Ferraz e Sasseron (2017) ampliam também o conhecimento sobre a influência das ações dos(as) docentes na argumentação dos(as) estudantes e concluem que a forma como o professor problematizou um objeto a ser compreendido influenciou diretamente na produção de argumentos pelos(as) estudantes. Suas análises das ações desse professor, baseada em um instrumento elaborado pelos autores, possibilitou caracterizar como o professor pode favorecer a argumentação de estudantes em contextos investigativos, apresentando os propósitos epistêmicos dele e as ações típicas relacionadas a cada propósito. Por exemplo, o propósito "Problematizar" corresponde a "proposições que tornam o objeto de estudo passível de investigação pelos alunos" (p. 48). As ações típicas relacionadas a esse propósito são propor um problema ou transformar uma situação ou dúvida em um problema a ser investigado pela turma.

Um outro instrumento de análise das ações docentes favoráveis à argumentação foi elaborado por Ibraim e Justi (2018) com base em referenciais e na prática de uma professora. Nesse caso, as ações são entendidas como um dos elementos essenciais do conjunto de conhecimentos para a ação docente em argumentação. Esses conhecimentos possibilitam "ensinar ciências envolvendo argumentação" (p. 315) e "engajar os alunos na vivência e reflexão sobre essa prática científica" (p. 315). Das 18 ações docentes podemos citar, como exemplo, "encorajar os alunos a participar do debate, a manifestar suas ideias" e "apresentar argumento(s) que desafie(m) a(s) ideia(s) do(s) aluno(s)." (p. 319).

Entendendo a argumentação como fundamental na construção coletiva de conhecimento, Larraín e Freire (2011) caracterizam ações docentes sob uma perspectiva que dá maior ênfase ao discurso. Essas ações podem estimular ou inibir a argumentação de estudantes desde etapas mais iniciais de escolarização. Por exemplo, "reconhecer a controvérsia e formulá-la, explícita e claramente para que todo o grupo possa percebêla, pensar sobre ela e, desse modo, se beneficiar do movimento dialético iniciado pelo colega" (p. 73). Além disso, as autoras apresentam evidências de que os(as) estudantes, desde pequenos(as), são capazes de contrapor ideias e que sua participação em situações que envolvem resolução de desacordos são o ponto de partida para a construção de entendimento sobre o aspecto estrutural da argumentação. 


\section{Noções de cultura e de argumentação que orientam o referencial teórico-metodológico do estudo}

A definição de cultura favorável à argumentação apresentada por Sandoval e colaboradores (2019) se aproxima da definição de cultura encontrada na Etnografia em Educação em que nos fundamentamos. Essa aproximação se dá pelo reconhecimento da importância da linguagem e do grupo para a construção da cultura. Dessa forma, análises das interações discursivas tornam-se fundamentais para compreendermos uma cultura da sala de aula favorável à argumentação.

Na perspectiva da Etnografia em Educação, a cultura é "um conjunto de princípios de práticas que são construídos por seus membros à medida que estabelecem papéis e relações, normas e expectativas, e direitos e obrigações que constituem o sentimento de pertença ao grupo local" (Spradley, 1998 citado por Green et al., 2005, p. 30). Para investigar uma cultura precisamos "focar no que os membros de uma sala de aula precisam saber, fazer, produzir e interpretar para participar na construção de eventos por meio dos quais conhecimento cultural e da disciplina escolar dessa sala de aula são desenvolvidos" (Rex, 2006, p. 4, tradução nossa ${ }^{3}$ ). No presente estudo, utilizamos essa definição de cultura de sala de aula proposta pela Etnografia em Educação para analisar como uma cultura favorável à argumentação pode ser construída.

Green et al. (2005) sugerem que essa noção de cultura não é fixa, pois os padrões de vida vão sendo construídos à medida que docentes e estudantes agem e interagem discursivamente ao longo do tempo e dos eventos. Além disso, normas e expectativas vão sendo estabelecidas, contestadas e redefinidas, implícita ou explicitamente (por exemplo exemplo, Dixon \& Green, 2005; McDonald \& Kelly, 2012). Dessa forma, para compreendermos as mudanças na cultura e nos processos argumentativos que ocorrem em cada sala de aula, precisamos estar atentos a esses aspectos.

Green et al. (2005) também destacam que a unidade analítica básica de etnografias de sala de aula é o grupo, não o indivíduo. Compreende-se que as ações de docentes e estudantes são moldadas pelas respostas (verbais ou não verbais) de outros membros da sala de aula (Dixon \& Green, 2005). Nesse sentido, podemos dizer que os membros de uma sala de aula influenciam-se mutuamente e as ações de cada membro contribui para o direcionamento do discurso. Além disso, essas diferentes formas de agir e reagir uns aos outros, que também são permeadas pelas diferentes trajetórias dos membros de uma sala de aula, podem resultar em diferentes maneiras de se construir uma cultura favorável à argumentação.

Além de explicitar em que definição de cultura nos fundamentamos, é importante esclarecer a que conceito de argumentação nos referimos no presente estudo e os motivos que nos conduziram a essa escolha.

3 "Focus on understanding what members of a classroom need to know, do, predict and interpret in order to participate in the construction of ongoing events through which cultural and subject matter knowledge of that classroom is developed" (Rex, 2006, p.4). 
No campo de pesquisa em Educação em Ciências, a argumentação/argumento tem recebido uma variedade de definições. Dessa forma, pode ser entendida/o como uma declaração e como um processo. Dependendo do estudo, pode ser abordado como estando relacionada/o ao contexto de diálogo ou ter lugar internamente na mente do indivíduo (ou ambos). Nesse sentido, em alguns casos, entende-se que a argumentação/ argumento pode ser construído socialmente ou produzido por um indivíduo. Outros autores apresentam uma concepção mais centrada na justificativa do conhecimento, outros na persuasão (Jiménez-Aleixandre \& Erduran, 2007). Ainda circulam perspectivas de que a argumentação/argumento é conflito, em que duas ou mais pessoas apresentam pontos de vista opostos e se responsabilizam pela defesa deles (Jiménez-Aleixandre \& Erduran, 2007; van Eemeren et al., 2002) ou pode ser dúvida, incerteza e questionamento a um ponto de vista ou argumento (van Eemeren et al., 2002). Alguns pesquisadores escolhem uma dessas visões, outros combinam várias delas (Jiménez-Aleixandre \& Erduran, 2007).

Como nas turmas investigadas não existia um fenômeno formal denominado “argumentação", recorremos às orientações de Green, Dixon e Zaharlick (2005). Segundo essas autoras, quando os membros do grupo não têm um "nome" para suas atividades, os pesquisadores podem "tomar decisões orientadas por princípios teóricos" (Green et al., 2005, p. 45).

Devido a esses contextos educacionais, buscamos uma teoria da argumentação que proporcionasse, ao máximo, a compreensão dos eventos a partir da perspectiva êmica (dos/as participantes), que é um princípio-chave da Etnografia em Educação. Encontramos na teoria da argumentação Pragma-dialética grande potencial, principalmente, em relação ao conceito de argumentação, aos pressupostos metateóricos e às ferramentas descritivas desta teoria.

Segundo van Eemeren et al. (2002, pp. xi-xii, tradução nossa ${ }^{4}$ ), "argumentação é uma atividade verbal, social e racional que visa convencer uma crítica razoável da aceitabilidade de um ponto de vista, apresentando uma constelação de uma ou mais proposições para justificar esse ponto de vista."

Esse conceito remete aos pressupostos metateóricos dessa teoria que podem ser relacionados com a Etnografia em Educação. Por exemplo, essa teoria, assim como a Etnografia em Educação, reconhece que, quando as pessoas usam a linguagem, elas estão fazendo algo. Além disso, por ser entendida como atividade social, o foco de análise é o grupo, não o indivíduo (van Eemeren et al., 2002; Castanheira et al., 2007).

A dimensão racional está relacionada a variações na racionalidade e na aceitabilidade de proposições e argumentos, pois dependem do que o ouvinte ou leitor legitima/valida e do que é adequado ao processo de resolução de cada diferença de opinião (van Eemeren \& Grootendorst, 2004). Essas variações, tanto na racionalidade quanto na aceitabilidade, são muito relevantes para o estudo de argumentação a partir de uma

4 argumentation is a verbal, social, and rational activity aimed at convincing a reasonable critic of the acceptability of a standpoint by putting forward a constellation of one or more propositions to justify this standpoint (Van Eemeren et al., 2002, pp.xi-xii). 
perspectiva etnográfica, pois possibilitam a caracterização das situações argumentativas a partir da perspectiva êmica (dos participantes) de grupos diversificados, respeitando as especificidades de cada grupo (ver Green et al., 2005).

Nesse conceito, também podemos perceber que van Eemeren et al. (2002) sugerem que a função da argumentação é resolver diferenças de opinião. Segundo essa teoria, a diferença de opinião surge quando uma pessoa apresenta um ponto de vista e outra(s) pessoa(s) - real(is) ou projetada(s) - submete $(\mathrm{m})$ esse ponto de vista a questões, dúvidas, objeções ou contra afirmações (van Eemeren et al., 2002). Nesse sentido, o que conta como argumentação vai além do conceito de conflito amplamente utilizado no campo da Educação em Ciências (Jiménez-Aleixandre \& Erduran, 2007).

$\mathrm{Na}$ Pragma-dialética, portanto, duas ou mais pessoas podem apresentar pontos de vistas opostos, como também podem apresentar dúvidas, incertezas e questões em relação a um ponto de vista. Esse aspecto é relevante, ao adotarmos uma perspectiva etnográfica, pois ampliando-se as situações consideradas argumentativas, podemos também identificar e caracterizar a argumentação que ocorre em grupos sociais minoritários e/ou que se comunicam predominantemente de forma indireta ou implícita.

Dessa forma, quando nos referirmos ao longo do texto à termos como "controvérsia", "desacordo" ou "diferença de opinião", estamos considerando tanto situações de conflito quanto as que envolvem dúvidas, questões e incertezas. Além disso, a partir da perspectiva da teoria da argumentação Pragma-dialética, tanto os contraargumentos quanto a resposta de rejeição propostas por Leitão (2000) são analisadas como posicionamentos antagonistas, pois são situações em que os participantes colocam em dúvida ou apresentam objeções a pontos de vista ou argumentos.

\section{Metodologia}

O estudo foi realizado em dois diferentes cenários educacionais em uma capital no sudeste do Brasil ${ }^{5}$, potencializando-se a ocorrência de diversos processos de construção de uma cultura favorável à argumentação. O primeiro foi uma sala de aula de Ciências da EJA no turno da noite de uma escola pública federal. No início da coleta de dados (2009), essa turma estava no primeiro ano de um projeto de extensão de uma universidade pública, que buscava possibilitar a conclusão dos anos finais do Ensino Fundamental. A turma tinha 25 estudantes ( 6 homens e 19 mulheres) com idade superior a 45 anos. O professor, Domingos ${ }^{6}$, formou-se em licenciatura em Ciências Biológicas durante o período de coleta de dados, mas tinha dois anos de experiência anterior. Suas aulas eram predominantemente expositivas-dialogadas. Contudo, eram muito interativas, principalmente, por encorajar estudantes a participarem e por fazer perguntas para avaliar sua compreensão.

\footnotetext{
5 Os "Casos" apresentados na presente pesquisa envolveram a participação de estudantes e professores. Embora essas pesquisas representassem riscos mínimos para os participantes e para suas instituições, foram respeitadas as normas e diretrizes estabelecidas pela Resolução 196/96 do Conselho Nacional de Saúde, com a aprovação do Comitê de Ética na Pesquisa da Universidade Federal de Minas Gerais sob os números de parecer ETIC 0472.0.203.000-09 (pesquisa do mestrado) e ETIC 0239.0.203.000-11 (pesquisa do doutorado). 6 Todos os nomes são pseudônimos que visam proteger o anonimato dos participantes da pesquisa.
} 
O segundo cenário foi uma sala de aula de Ciências do $8^{\circ}$ ano do Ensino Fundamental regular de uma escola pública municipal. A turma tinha 30 estudantes (12 homens e 18 mulheres) com 13 a 15 anos. A professora, Beatriz era professora da turma desde $o$ ano anterior e tinha licenciatura em Ciências Biológicas, mestrado em Educação. No ano da coleta de dados (2011), ela tinha sete anos de experiência como docente. Suas aulas, também eram predominantemente expositivas-dialogadas, bastante interativas e incluíram leitura, resolução de exercícios e atividades no laboratório. ${ }^{7}$

\section{Caracterização da pesquisa, construçãodos dados eprocedimentos de análise}

Esta investigação foi orientada por uma perspectiva naturalista de pesquisa qualitativa (Lincoln \& Gubba, 1985) e caracteriza-se como um estudo de caso de tipo múltiplo e de natureza mais instrumental (Stake, 1998), informado pela Etnografia Interacional (Castanheira et al., 2007; Dixon \& Green, 2005; Green et al., 2005).

A primeira autora conduziu observação participante (Spradley, 1980) com registro em notas de campo, combinado a registro em áudio e vídeo (Skukauskaité, Liu, \& Green, 2007) por um período de oito meses na sala de aula da EJA (2009-2010) e dez meses na sala de aula do $8^{\circ}$ ano (2011).

Inicialmente foram realizadas análises macroscópicas, para cada turma separadamente, que envolveram a construção de mapas de eventos e linhas do tempo com diferentes níveis de detalhamento (por exemplo exemplo, Dixon \& Green, 2005). Através dessas análises, foi possível identificar eventos-chave envolvendo argumentação relacionada à aprendizagem de conceitos, práticas e discursos relacionados a diferentes tópicos abordados nas aulas (por exemplo exemplo, Duschl, 2008). Esses eventos, situações argumentativas, foram considerados mais significativos para os participantes da pesquisa. Os critérios adotados para seleção foram: i) a participação de vários participantes na resolução de uma diferença de opinião e; ii) o tempo de participação com duração superior a cinco minutos.

Os três eventos na turma da EJA e os dois eventos na turma do $8^{\circ}$ ano (com duração de 5 a 30 minutos) foram transcritos palavra-a-palavra (Bloome et al., 2005) e analisados separadamente. Ou seja, analisamos as semelhanças e diferenças entre as situações argumentativas de cada uma das turmas, buscando compreender os processos argumentativos nessa turma. Somente depois de compreender os processos de cada turma, contrastamos os eventos das duas turmas para analisar semelhanças e diferenças, nos questionando como esses processos contribuíam para a construção de uma cultura favorável à argumentação.

Inicialmente, as transcrições foram analisadas tendo como principal referência a dimensão descritiva da teoria da argumentação Pragma-dialética (van Eemeren et

7 Em trabalhos anteriores, investigamos os processos argumentativos na sala de aula da Educação de Jovens e Adultos (EJA) (Munford \& Teles, 2015) e na turma do $8^{\circ}$ ano do ensino regular (Munford \& Teles, 2013) separadamente. Dessa forma, apresentamos nesses estudos mais detalhes sobre cada turma e como os processos argumentativos se desenvolveram. 
al., 2002). Na Pragma-dialética essas ferramentas descritivas são usadas para avaliar o discurso argumentativo, considerando o que os autores denominaram de discussão crítica. No presente estudo, por outro lado, não temos como objetivo avaliar o discurso, mas dar maior visibilidade aos processos argumentativos e à construção de uma cultura de sala de aula favorável à argumentação por meio das interações discursivas. Nesse sentido, essas ferramentas descritivas foram adaptadas considerando-se aspectos da Etnografia em Educação e características de uma cultura favorável à argumentação supracitados.

Em nossas análises, portanto, buscamos descrever: i) quando, como e por quem os desacordos foram gerados; ii) quais elementos estavam implícitos ou explícitos e iii) o processo de resolução dos desacordos, considerando-se: a) como os membros do grupo se posicionaram e interagiram discursivamente para defender seu ponto de vista e argumentos (protagonista) e/ou para colocar dúvidas, incertezas, objeções ou contra-posições a algum ponto de vista ou argumento (antagonista); e b) como, nessas interações discursivas, desacordos mais amplos (diferença de opinião principal) foram resolvidos a partir de desacordos mais específicos (diferenças de opinião subordinadas).

Durante as análises, construímos quadros que possibilitaram relacionar as interações discursivas com as análises a partir das categorias supracitadas (Figura 1). Esses quadros mapearam todo o processo argumentativo de cada evento. A partir das informações contidas nesses quadros, construímos sínteses relacionadas a cada categoria de análise e contrastamos essas sínteses com as de outros eventos da mesma turma para compreender os processos argumentativos de cada sala de aula (Munford \& Teles, 2015; Munford \& Teles, 2013). No presente estudo, contrastamos os eventos das duas turmas, buscando identificar semelhanças e diferenças entre os processos argumentativos e suas relações com a construção de uma cultura favorável à argumentação.

$\mathrm{O}$ trecho da Figura 1 corresponde à aula sobre Sistema $\mathrm{ABO}$ da turma de EJA. Na primeira coluna, inserimos o número da Linha $(\mathrm{L})$, que corresponde à mudança de quem fala ao longo da interação. Nesse exemplo, representamos o trecho de transcrição da L66-68, que significa que há 65 linhas de interações discursivas antes das representadas ${ }^{8}$. $\mathrm{Na}$ última coluna, buscamos representar graficamente as análises descritas na coluna anterior, mostrando a articulação entre os diferentes elementos da argumentação. PVal' $=1^{\circ}$ ponto de vista da diferença de opinião subordinada "a"; bII1.1.1 = subargumento 1.1.1 da diferença de opinião "bII"; PVal' como bII1.1.1 = conteúdo do argumento bII1.1.1 é o mesmo do PVal'; PVbII1 = $1^{\circ}$ ponto de vista da $2^{\text {a }}$ diferença de opinião subordinada "bII"; PVbII2 $=2^{\circ}$ ponto de vista da $2^{a}$ diferença de opinião subordinada "bII"; PVbII3 = $3^{\circ}$ ponto de vista da $2^{\text {a }}$ diferença de opinião subordinada "bII"; PVa2' como bII2.1.1 = conteúdo do argumento bII2.1.1 é o mesmo do PVa2'; a apóstrofe = elemento está implícito no discurso, como em PVal'.

8 Para facilitar a identificação do momento da história da turma ao qual se referem os trechos de transcrição citados, numeramos as linhas em uma única sequência numérica, ou seja, a primeira linha dos eventos da segunda aula corresponde à sequência da última linha dos eventos da primeira aula e assim sucessivamente. Entretanto, é importante destacar que, como mostram as Figura 2 e 3, esses eventos não ocorreram imediatamente um após o outro. 
Figura 1. Trecho do Quadro que relaciona discurso e análises a partir da Pragma-dialética e suas respectivas adaptações

\begin{tabular}{|c|c|c|c|c|}
\hline $\begin{array}{l}\text { Linha } \\
\text { (L) }\end{array}$ & $\begin{array}{l}\text { Transcrição: unidades } \\
\text { de mensagem (UM) }\end{array}$ & $\begin{array}{l}\text { Elementos } \\
\text { não- } \\
\text { verbais }\end{array}$ & Análises & Representação gráfica \\
\hline 66 & $\begin{array}{l}\text { Professor: } \\
\text { 1. } \begin{array}{l}\text { Porque senão } \\
\text { o anticorpo } \\
\text { vai combater o } \\
\text { antígeno/ }\end{array} \\
\text { 2. Sempre é assim/ } \\
\text { 3. o anticorpo é uma } \\
\text { defesa que vai } \\
\text { reconhecer isso } \\
\text { aqui/ } \\
\text { como ameaça / } \\
\text { 5. e vai combater a } \\
\text { própria hemácia } \\
\text { dele/ }\end{array}$ & $\begin{array}{l}\text { UM3 } \\
\text { (mostra o } \\
\text { antígeno } \\
\text { na figura } \\
\text { no quadro- } \\
\text { negro) }\end{array}$ & $\begin{array}{l}\text { UM1-5 Professor } \\
\text { responde a aluna, } \\
\text { usando PVa1 como } \\
\text { UM6-9 Explicita os } \\
\text { três pontos de vista } \\
\text { em discussão. Essa } \\
\text { ação pode contribuir } \\
\text { para a construção } \\
\text { de uma cultura em } \\
\text { que várias visões são } \\
\text { legítimas. argumento } \\
\text { de bII1.1.1 e } \\
\text { repetindo L34. } \\
\text { UM6-9 Explicita os } \\
\text { três pontos de vista } \\
\text { em discussão. Essa } \\
\text { ação pode contribuir } \\
\text { para a construção } \\
\text { de uma cultura em } \\
\text { que várias visões são } \\
\text { legítimas. }\end{array}$ & 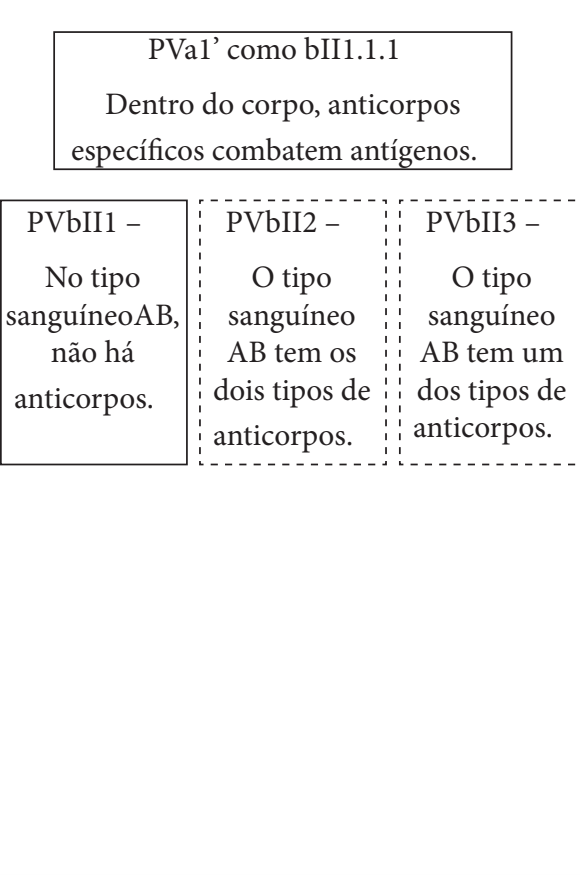 \\
\hline 67 & $\begin{array}{l}\text { Alunos: } \\
\text { 1. Os dois. }\end{array}$ & & $\begin{array}{l}\text { Alunos insistem no } \\
\text { PVbII2. }\end{array}$ & $\begin{array}{l}\text { PVbII2 - O tipo sanguíneo AB } \\
\text { tem os dois tipos de anticorpos. }\end{array}$ \\
\hline 68 & $\begin{array}{l}\text { Professor: } \\
\text { 1. Os dois? }\end{array}$ & & $\begin{array}{l}\text { Antagonista: } \\
\text { Questionamento }\end{array}$ & $?$ \\
\hline
\end{tabular}

\section{Resultados - Contraste entre os processos argumentativos}

Conforme mencionado anteriormente, os processos argumentativos correspondentes a cada turma separadamente foram publicados em outros trabalhos. No presente estudo, contrastamos todos os eventos das duas turmas, buscando responder nossas questões de pesquisa. Nessa seção, organizamos os contrastes a partir das ferramentas descritivas da Pragma-dialética supracitadas, visando responder nossa primeira questão: "Em que aspectos os processos argumentativos em uma turma do $8^{\circ}$ ano do ensino regular e da EJA se assemelham e se diferenciam?"

Nas Figuras 2 e 3 localizamos os eventos em uma linha do tempo e apresentamos um sumário dos eventos selecionados, respectivamente, das aulas de Ciências da EJA e do $8^{\circ}$ ano do ensino regular. 
Figura 2. Linha do tempo com caracterização geral das aulas da turma da EJA

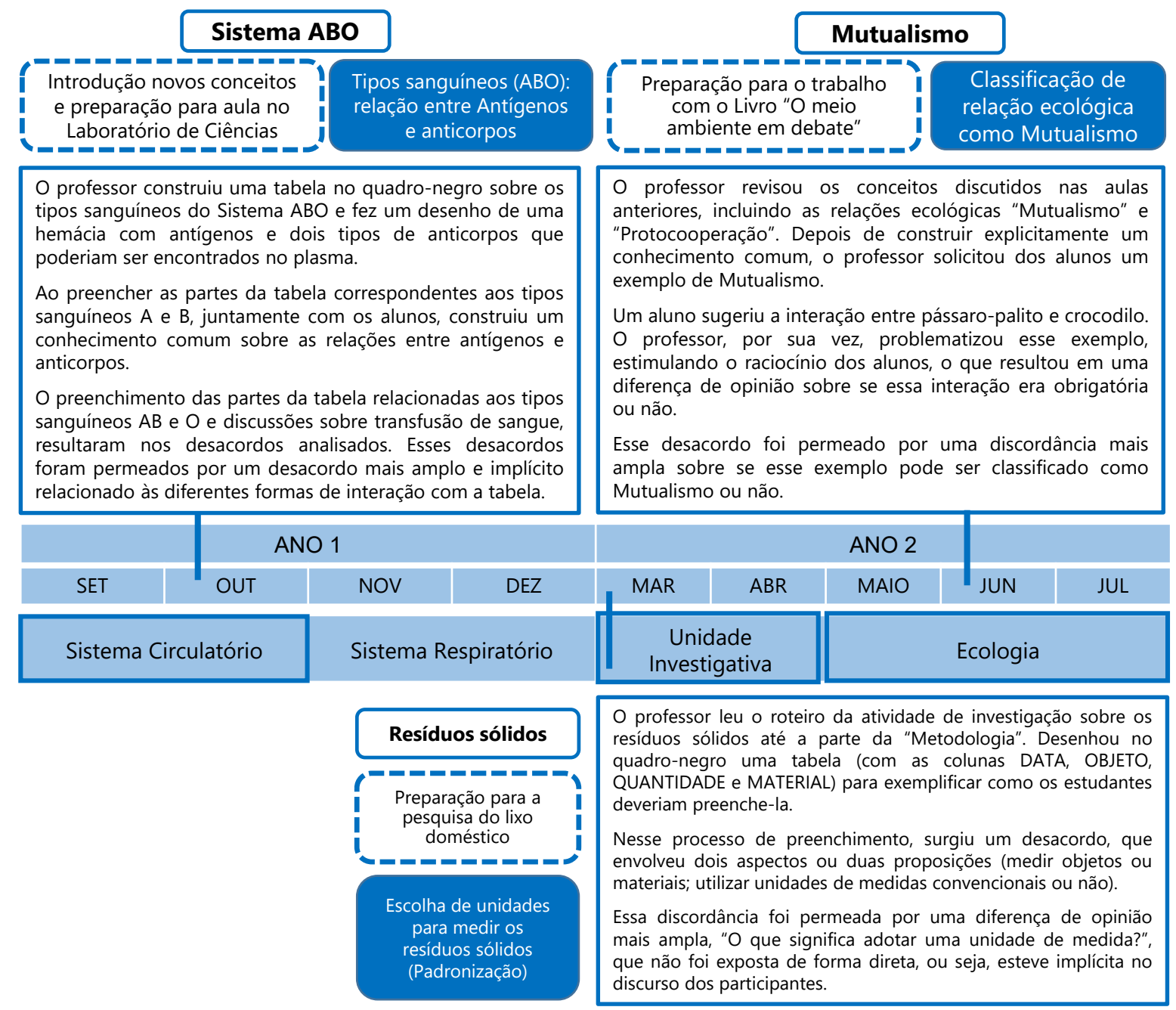

O quadrado com borda pontilhada traz informações sobre o contexto instrucional em que a situação argumentativa está situada. O quadrado azul indica a principal a temática envolvendo a argumentação. 
Figura 3. Linha do tempo com caracterização geral das aulas da turma do $8^{\circ}$ ano

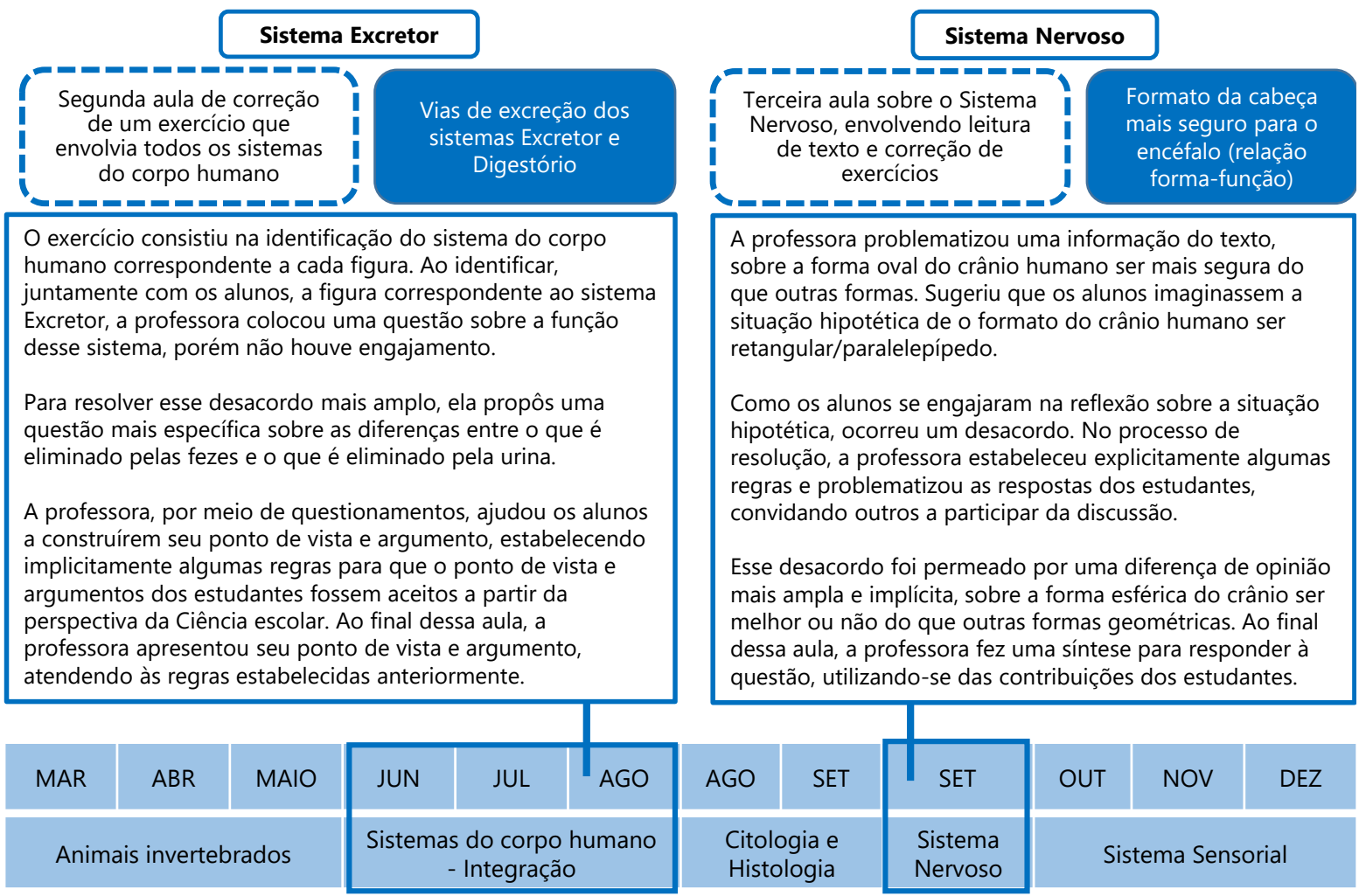

O quadrado com borda pontilhada traz informações sobre o contexto instrucional em que a situação argumentativa está situada. O quadrado azul indica a principal a temática envolvendo a argumentação.

\section{Promovendo desacordos}

Conforme apresentado nas Figuras 2 e 3, podemos observar quando, ou seja, em que contexto, desacordos surgiram em cada sala de aula. Na turma do $8^{\circ}$ ano (Figura 3), os desacordos da aula sobre Sistema Excretor surgiram durante a correção de exercícios e, na aula sobre Sistema Nervoso, surgiram após a leitura coletiva de um texto didático sobre o tema. Na turma da EJA (Figura 2), por outro lado, os desacordos surgiram durante a introdução de novos conceitos na aula sobre Sistema ABO. Durante dúvidas relacionadas ao preenchimento de um roteiro de uma investigação sobre o lixo doméstico na aula sobre Resíduos sólidos. Na aula sobre Mutualismo, por outro lado, desacordos surgiram durante o aprofundamento de conceitos relacionados às relações ecológicas, visando à preparação para a leitura de um livro paradidático sobre meio ambiente.

Exceto pela aula sobre Resíduos sólidos, que apresenta uma abordagem mais investigativa, nas outras aulas, as situações em que ocorreram argumentação foram predominantemente aquelas em que se discutiram aspectos conceituais sem muita margem para variação de posição, a partir da perspectiva da Educação em Ciências. 
A partir das ferramentas descritivas da Pragma-dialética orientadas por uma perspectiva etnográfica, além de quando, também é importante observar por quem e como surgiram os desacordos. Em ambas as salas de aula investigadas, em todos os eventos, quem iniciou desacordos foram os professores (Figura 4).

Figura 4. Contraste de como os desacordos emergiram nos eventos de argumentação de ambos os cenários

\begin{tabular}{|c|c|c|c|c|}
\hline \multicolumn{3}{|c|}{ Eventos da turma da EJA } & \multicolumn{2}{|l|}{ Eventos $8^{\circ}$ ano } \\
\hline Sistema ABO & $\begin{array}{l}\text { Resíduos } \\
\text { Sólidos }\end{array}$ & Mutualismo & Sistema Excretor & Sistema Nervoso \\
\hline $\begin{array}{l}\text { P questionou } \\
\text { resposta dos E sobre } \\
\text { conceitos ainda } \\
\text { não abordados em } \\
\text { sala: antígeno e } \\
\text { anticorpos. }\end{array}$ & $\begin{array}{l}\text { P questionou } \\
\text { o método de } \\
\text { medida de } \\
\text { matéria orgânica } \\
\text { dos(as) E. }\end{array}$ & $\begin{array}{l}\text { P questionou } \\
\text { exemplo de } \\
\text { Mutualismo } \\
\text { dado por E. }\end{array}$ & $\begin{array}{l}\text { P questionou } \\
\text { resposta sobre } \\
\text { função do Sistema } \\
\text { dada por E sobre } \\
\text { tema já abordado } \\
\text { em sala. }\end{array}$ & $\begin{array}{l}\text { P propôs situação } \\
\text { hipotética sobre } \\
\text { formato do crânio } \\
\text { humano. }\end{array}$ \\
\hline
\end{tabular}

$P=\operatorname{professor}(a) ; E=$ estudantes.

$\mathrm{Na}$ Figura 4, podemos também ter um panorama de como desacordos foram iniciados. Na turma da EJA, todos os desacordos foram iniciados por meio de questionamentos do professor. Enquanto que na turma do $8^{\circ}$ ano, tanto questionamento da professora quanto a proposição de uma situação hipotética, geraram desacordos.

$\mathrm{Na}$ Figura 5, podemos observar que o ponto de partida para a construção do desacordo foi a situação hipotética proposta pela professora na aula sobre Sistema Nervoso, a partir da problematização de uma informação do texto didático. Na L126, em itálico, a professora propôs a situação hipotética. A aluna Joana fez um comentário (L127), a professora chamou a atenção da turma para o raciocínio dessa aluna, solicitando implicitamente que a mesma explicasse sua ideia para a turma (em itálico L128). A aluna repetiu sua fala, mudando "não ter problema" por "ia ser mais seguro" (L129). A professora, então questionou esse posicionamento da aluna e convidou outros estudantes a se posicionar (L130). Como vários estudantes responderam que discordavam (L131), iniciou-se o processo de resolução desse desacordo.

Nas outras aulas, observamos que ambos os professores questionaram as respostas/ propostas dos(as) estudantes. A partir de uma perspectiva ética (não membro do grupo) esses questionamentos poderiam corresponder a perguntas de aprofundamento. Entretanto, analisamos as perguntas dos professores e ações subsequentes dos membros de cada sala de aula, buscando apreender a perspectiva dos participantes, como orientado pela Etnografia em Educação (por exemplo exemplo, Green et al., 2005; Rex, 2006). Assim, observamos que as perguntas, para cada grupo, correspondiam a questionamentos, pois resultaram em diferenças de opinião em que o grupo se engajou para resolver, configurando-se como uma situação de argumentação como proposto pela teoria Pragma-dialética (van Eemeren et al., 2002). 
Figura 5. Trecho da transcrição da aula sobre Sistema Nervoso - turma $8^{\circ}$ ano

\begin{tabular}{|c|c|}
\hline Linha (L) & Interações discursivas \\
\hline 126 & $\begin{array}{l}\text { Professora: o crânio / os ossos do crânio / que são duros e se encaixam formando essa } \\
\text { bola/ essa estrutura arredondada que é a nossa cabeça / Aqui no texto / fala que uma } \\
\text { das formas mais fortes que se conhece é uma bola rígida / Aí / podia pensar assim / } \\
\text { (os alunos conversam) se vocês forem bobos / vocês vão fazer comentários muito sem } \\
\text { sentido / olha só porquê? / Imagina que nossa cabeça / ao invés de ser com esse formato } \\
\text { / se ela fosse um quadrado ou um retângulo ou paralelepípedo / formato de caixa / Que } \\
\text { bom que não tem nenhum bobo aqui / porque na outra turma / eu fui falar isso / e o } \\
\text { povo ficou falando / 'ai que esquisito! Credo!' / Só que você tem que pensar o seguinte } \\
\text { / se todo mundo tivesse a cabeça quadrada / o padrão ia ser outro / o normal ia ser } \\
\text { quadrada / Imagina todos nós com a cabeça quadrada / e um dia eu chegava e falava } \\
\text { assim / "Então gente / se a gente tivesse a cabeça arredondada / Nossa / a gente ia ser } \\
\text { feio demais" (risos) / Pra gente / o normal é esse / o redondo / }\end{array}$ \\
\hline 127 & $\begin{array}{l}\text { Joana: pelo menos / se a gente tivesse a cabeça quadrada / não ia ter tanto problema / } \\
\text { porque quando cair / a gente ia ficar reto / }\end{array}$ \\
\hline 128 & $\begin{array}{l}\text { Professora: Aqui / a Joana estava falando o seguinte / Fabrício / vira para frente / senão } \\
\text { eu vou voltar você pra lá / Vamos lá / (virou para o quadro e voltou para os alunos) / } \\
\text { Ela defendeu o seguinte / que se a gente tivesse a cabeça quadrada / quando a gente fosse } \\
\text { cair / o que ia acontecer? }\end{array}$ \\
\hline 129 & Joana: a gente ia ficar reto / em vez de (inaudível) / Ia ser mais seguro / \\
\hline 130 & $\begin{array}{l}\text { Professora: mais seguro? / Então / seria mais esperto / a cabeça quadrada? Alguém } \\
\text { discorda? / }\end{array}$ \\
\hline 131 & Vários alunos: discordo / \\
\hline
\end{tabular}

Por questões de espaço, apresentamos, como exemplo desses questionamentos, a aula sobre Sistema ABO da turma da EJA. Nessa aula, o professor estava introduzindo o conhecimento sobre interação entre antígenos e anticorpos em relação aos tipos sanguíneos desse sistema, ou seja, era um momento em que os(as) estudantes tomavam um primeiro contato com aquele conhecimento. O professor solicitou a participação da turma para o preenchimento de uma tabela com informações relacionadas a esses tipos sanguíneos. O desacordo surgiu quando o professor perguntou quais eram os anticorpos do tipo AB (em itálico na L54, Figura 6) e as estudantes responderam A e B, direta (L55 e L58) ou indiretamente (L57). O professor questionou esta resposta (L59).

A pergunta da aluna Maria Gabriela (L60) e a pergunta do professor (L61), solicitando mais explicações sobre o que a aluna quis dizer, são algumas das evidências ao longo desse evento de que o desacordo estava bastante relacionado ao conhecimento sobre formas de se comunicar no campo das Ciências da Natureza, de forma articulada ao domínio de conhecimentos conceituais. Ler e completar uma tabela é uma ação informada por normas construídas a partir da participação em práticas sociais de uma certa comunidade.

Para o professor, tais práticas vinham da Ciência acadêmica e eram "deslocadas" para o contexto escolar: a tabela representava fenômenos (L54 e L59) e era usada para "falar Ciências". Para estudantes, a tabela era um objeto "escolar", no sentido de que não 
estava contextualizada em práticas e discursos da Ciência. Como ilustrado pela fala da aluna Maria Gabriela (L60), seguia-se uma "regra" de que "se anti-A ocorre junto com B e anti-B com A, então anti-A e anti-B estão presentes com AB”.

Figura 6. Trecho da transcrição da aula sobre Sistema ABO — turma EJA

\begin{tabular}{|l|l|}
\hline 54 & $\begin{array}{l}\text { Professor: Ele tem os dois / Vou colocar a legenda aqui / tem o antígeno A / que é a bolinha / } \\
\text { e tem o antígeno B / que é o triângulo / E o anticorpo vai combater o antígeno / Ele não vai se } \\
\text { ligar no antígeno lá? / Ele não vai ter a pontinha específica para ligar no antígeno? / E nós temos } \\
\text { estes dois tipos de anticorpos / o anti-B e o anti-A / Será que quem tem o sangue AB vai ter qual } \\
\text { tipo de anticorpo no plasma dele? / }\end{array}$ \\
\hline 55 & Bianca: O A e B / \\
\hline 56 & Professor: ah / \\
\hline 57 & Margareth: Não é os dois não? / \\
\hline 58 & Érica: Vai ter o anticorpo A e B / \\
\hline 59 & $\begin{array}{l}\text { Professor: O Anticorpo A e B? / Mas aí / olha só / se ele tiver o anticorpo A e B / se o sangue } \\
\text { dele for assim / Não desenha não / agora só presta atenção aqui / É assim / vai haver esses } \\
\text { dois anticorpos (desenha os anticorpos) / Esses anticorpos vão ligar na hemácia dele / e vão } \\
\text { reconhecer a própria hemácia dele como ameaça / Vai destruir / }\end{array}$ \\
\hline 60 & Maria Gabriela: Então tem que ser ao contrário sempre? / \\
\hline 61 & Professor: Ao contrário como assim? / Então vai ter qual anticorpo no plasma? / \\
\hline
\end{tabular}

Em síntese, podemos dizer que os desacordos surgiram em contextos predominantemente curriculares, em que os conceitos tiveram mais centralidade. Além disso, as ações dos professores, seja por meio de questionamentos ou propondo uma situação hipotética, foram centrais para os desacordos serem iniciados. Como supracitado, essas situações configuraram-se como desacordos devido ao engajamento dos membros de cada grupo nos processos de resolução dessas diferenças de opinião. Esses processos serão descritos nas próximas seções.

\section{Processos de resolução de desacordo: Relações entre diferenças de opinião}

Depois de iniciados os desacordos, de forma processual e diversificada, professores e estudantes interagiram discursivamente visando resolvê-los ${ }^{9}$. Nessa seção, vamos olhar para esses processos a partir de uma visão mais panorâmica, considerandose as relações entre as diferenças de opinião.

$\mathrm{Na}$ aula sobre Sistema ABO (EJA), por exemplo, o processo de resolução dos desacordos foi diferente de todos os outros processos (Figura 7). Nessa aula, professor e estudantes não explicitaram, nas interações discursivas, o desacordo mais amplo (principal) relacionado às diferenças nas formas de interpretação da tabela. Assim, quatro desacordos mais específicos (subordinados) explícitos foram iniciados, um relacionado aos anticorpos presentes no tipo sanguíneo $\mathrm{AB}$ (mencionado anteriormente); e outros

9 Consideramos que os desacordos foram resolvidos quando os participantes pararam de se engajar no processo, independentemente de haver ou não consenso. 
três referentes à transfusão de sangue, principalmente do tipo sanguíneo $\mathrm{O}$.

Nas outras aulas, por outro lado, houve uma diferença de opinião principal, que foi explicitada nas interações discursivas nas aulas sobre Mutualismo (EJA) e Sistema Excretor ( $8^{\circ}$ ano) e estiveram implícitas nas aulas sobre Resíduos sólidos (EJA) e Sistema Nervoso ( $8^{\circ}$ ano). Buscando resolver o desacordo mais amplo, surgiram diferenças de opinião mais específicas, que, em todas as aulas, foram explicitadas nas interações discursivas.

Figura 7. Contraste das relações entre as diferenças de opinião principal e subordinada(s)

\begin{tabular}{|l|l|l|l|l|}
\hline \multicolumn{3}{|c|}{ Turma da EJA } & \multicolumn{2}{c|}{ Turma do 8 ano } \\
\hline Sistema ABO & Resíduos Sólidos & Mutualismo & Sistema Excretor & Sistema Nervoso \\
\hline & DO p (implícita) & DO p (implícita) & DO p (implícita) & DO p (explícita) \\
DO s (explícitas) & DO s (explícita) & DO s (explícita) & $\begin{array}{c}\text { DO s (explícita) } \\
\text { DO s (explícita) }\end{array}$ \\
\hline
\end{tabular}

DO $\mathbf{p}=$ diferença de opinião principal; DO $\mathbf{s}=$ diferença de opinião subordinada.

Estes resultados, portanto, evidenciam que não há uma forma única, universal, fixa e pré-estabelecida para a resolução de desacordos. Há situações em que a diferença de opinião não está dada e/ou não é consciente para os participantes (possivelmente até o próprio posicionamento) e a contraposição de ideias vai possibilitando uma tomada de consciência da diferença de opinião (aula Sistema ABO). Em outras situações a professora intencionalmente explicitava diferenças de opinião para promover a aprendizagem. $\mathrm{Na}$ próxima seção, apresentamos mais evidências dessa diversidade, destacando os posicionamentos e interação dos membros do grupo.

\section{Processos de resolução de desacordo: Posicionamentos e interação}

Nessa seção, descrevemos os processos de resolução dos desacordos, considerandose como os membros do grupo se posicionaram e interagiram discursivamente para defender seu ponto de vista e argumentos (protagonista) e/ou para colocar dúvidas, incertezas, objeções ou contra-posições a algum ponto de vista ou argumento (antagonista). Inicialmente, apresentamos, em uma visão panorâmica, o contraste entre duas salas de aula relacionado aos professores e depois o contraste entre duas salas de aula referente aos(às) estudantes. Posteriormente, apresentamos trechos de interações discursivas para exemplificar alguns aspectos dos processos de resolução de desacordos.

Como discutimos anteriormente, os desacordos surgiram principalmente devido às ações dos professores. Eles também tiveram um papel fundamental nos processos 
de resolução das diferenças de opinião. Contudo, as formas de participação dos(as) estudantes também contribuíram muito no sentido de aumentar a diversidade de processos argumentativos.

Ao contrastar todos os eventos, em relação aos posicionamentos e às formas de interação dos professores (Figura 8), podemos observar, nessa perspectiva panorâmica, que os docentes agiram tanto no sentido de defender seus pontos de vista (protagonistas) quanto agiram como antagonistas, principalmente através de questões. Tais questões possibilitaram que os professores mantivessem seu posicionamento implícito ${ }^{10}$ ao longo de grande parte do evento e foram importantes para promover a participação dos(as) estudantes de diferentes formas.

Figura 8. Contraste dos posicionamentos e formas de interação do(a) professor(a) em ambos os cenários

\begin{tabular}{|c|c|c|c|c|}
\hline \multicolumn{3}{|c|}{ Eventos da turma da EJA } & \multicolumn{2}{|c|}{ Eventos $8^{\circ}$ ano } \\
\hline Sistema ABO & $\begin{array}{l}\text { síduos } \\
\text { lidos }\end{array}$ & Mutualismo & Sistema Excretor & Sistema Nervoso \\
\hline $\begin{array}{l}\text { P agiu como } \\
\text { protagonista } \\
\text { e antagonista, } \\
\text { principalmente } \\
\text { de forma } \\
\text { implícita, feito } \\
\text { por meio de } \\
\text { questões. }\end{array}$ & $\begin{array}{l}\text { P agiu como } \\
\text { protagonista } \\
\text { (para múltiplos } \\
\text { pontos de } \\
\text { vista) de } \\
\text { forma explícita } \\
\text { e como } \\
\text { antagonista aos } \\
\text { pontos de vista } \\
\text { defendidos por } \\
\text { estudantes. }\end{array}$ & $\begin{array}{l}\text { P agiu como } \\
\text { protagonista } \\
\text { e antagonista, } \\
\text { de forma } \\
\text { implícita } \\
\text { por meio de } \\
\text { questões. }\end{array}$ & $\begin{array}{l}\text { P convidou os(as) } \\
\text { estudantes a assumirem } \\
\text { uma posição e propôs, de } \\
\text { forma implícita, normas } \\
\text { para a argumentação. P } \\
\text { agiu como protagonista e } \\
\text { antagonista implicitamente. } \\
\text { P apresentou seu ponto de } \\
\text { vista explicitamente no final } \\
\text { da interação, atendendo } \\
\text { às normas estabelecidas } \\
\text { anteriormente. }\end{array}$ & $\begin{array}{l}\text { P questionou os(as) } \\
\text { E e estabeleceu } \\
\text { explicitamente } \\
\text { normas para a } \\
\text { argumentação. P } \\
\text { apresentou seu } \\
\text { ponto de vista no } \\
\text { final da interação, } \\
\text { sintetizando os } \\
\text { argumentos e } \\
\text { contra-argumentos } \\
\text { dos(as) E’s. }\end{array}$ \\
\hline
\end{tabular}

$\mathbf{P}=$ professor $(\mathrm{a}) ; \mathbf{E}=$ estudantes.

Além desses aspectos comuns, podemos observar algumas especificidades. Nas aulas da EJA sobre Resíduos sólidos e Mutualismo, mesmo quando os posicionamentos e argumentos do professor estavam explícitos, os desacordos continuaram. Enquanto que nas aulas sobre Sistema ABO (EJA), Sistema Excretor ( $8^{\circ}$ ano) e Sistema Nervoso ( $8^{\circ}$ ano), os desacordos foram encerrados após os posicionamentos e argumentos dos docentes ficarem explícitos. Na turma do $8^{\circ}$ ano, a professora também definiu algumas normas para a argumentação, que estavam implícitas na aula sobre Sistema Excretor e foram atendidas quando a professora explicitou seu posicionamento e argumentos. $\mathrm{Na}$ aula sobre Sistema Nervoso, por outro lado, essas normas estavam explícitas e o ponto de vista da professora foi uma síntese do posicionamento e dos argumentos que os(as) estudantes apresentaram ao longo da discussão.

10 Entendemos como posicionamento implícito, quando a(s) questão(ões) colocada(s) por professor(a) ou estudantes trazem elementos de seu posicionamento. 
Com relação aos posicionamentos e interação dos(as) estudantes, em uma visão panorâmica (Figura 9), observa-se que em ambas as turmas, os(as) estudantes foram responsivos aos questionamentos do(a) professor(a) e agiram como protagonistas, usando principalmente experiências do cotidiano para construir seus argumentos. Entretanto, os(as) estudantes também agiram como antagonistas quando interagiram mais com os pares e/ou apresentaram um conhecimento científico/informação de um livro/texto.

Figura 9. Contraste dos posicionamentos e formas de interação dos(as) estudantes em ambos os cenários

\begin{tabular}{|c|c|c|c|c|}
\hline \multicolumn{3}{|c|}{ Eventos da turma da EJA } & \multicolumn{2}{|c|}{ Eventos $8^{\circ}$ ano } \\
\hline Sistema $\mathrm{ABO}$ & Resíduos Sólidos & Mutualismo & $\begin{array}{l}\text { Sistema } \\
\text { Excretor }\end{array}$ & $\begin{array}{l}\text { Sistema } \\
\text { Nervoso }\end{array}$ \\
\hline $\begin{array}{l}\text { E foram } \\
\text { responsivos(as) } \\
\text { a P. Interagiram } \\
\text { principalmente } \\
\text { com P. } \\
\text { Agiram como } \\
\text { protagonistas, } \\
\text { se } \\
\text { posicionando } \\
\text { implicitamente } \\
\text { e interpretando } \\
\text { a tabela a partir } \\
\text { de silogismos. }\end{array}$ & $\begin{array}{l}\text { E foram } \\
\text { responsivos(as) } \\
\text { às questões de P. } \\
\text { Interagiram com } \\
\text { outros(as) E e } \\
\text { com P. Diversas } \\
\text { interações: ponto } \\
\text { de vista sem } \\
\text { argumento, ponto } \\
\text { de vista tentando } \\
\text { conciliar outros } \\
\text { pontos de vistas } \\
\text { e apoio ao ponto } \\
\text { de vista defendido } \\
\text { por P. E's agiram } \\
\text { explicitamente } \\
\text { como protagonistas } \\
\text { e antagonistas. }\end{array}$ & $\begin{array}{l}\text { E foram } \\
\text { responsivos(as) } \\
\text { às questões de P. } \\
\text { Interagiram com } \\
\text { outros(as) E e } \\
\text { com P. Pontos de } \\
\text { vista e argumentos } \\
\text { explícitos. Agiram } \\
\text { como Protagonista } \\
\text { e antagonistas. } \\
\text { Usaram } \\
\text { informações } \\
\text { do livro e de } \\
\text { experiências do } \\
\text { cotidiano para } \\
\text { estruturar os } \\
\text { argumentos. }\end{array}$ & $\begin{array}{l}\text { E são } \\
\text { responsivos(as) às } \\
\text { questões de P. São } \\
\text { explicitamente } \\
\text { protagonistas, } \\
\text { reestruturando } \\
\text { ponto de vista } \\
\text { e argumentos. } \\
\text { Interagiram } \\
\text { principalmente } \\
\text { com P e usaram } \\
\text { experiências do } \\
\text { cotidiano para } \\
\text { estruturar os } \\
\text { argumentos. }\end{array}$ & $\begin{array}{l}\text { E foram } \\
\text { responsivos(as) } \\
\text { às questões de P. } \\
\text { Interagiram com } \\
\text { os outros(as) E } \\
\text { e com P. Agiram } \\
\text { explicitamente } \\
\text { como } \\
\text { protagonistas } \\
\text { e antagonistas. } \\
\text { Alguns E } \\
\text { defenderam o } \\
\text { mesmo ponto } \\
\text { de vista de } \\
\text { P e usaram } \\
\text { informação do } \\
\text { texto lido pela } \\
\text { turma para } \\
\text { estruturar os } \\
\text { argumentos. }\end{array}$ \\
\hline
\end{tabular}

$\mathbf{P}=$ professor $(\mathrm{a}) ; \mathbf{E}=$ estudantes.

Em ambas as turmas, a maior interação entre pares e o uso de recursos como livro/texto ocorreram nas aulas sobre Mutualismo (EJA) e Sistema Nervoso ( $8^{\circ}$ ano). Considerando o momento de formação das turmas com o(a) docente, essas aulas ocorreram: i) na turma da EJA, aproximadamente após 18 meses; ii) na turma de $8^{\circ}$ ano, aproximadamente após 21 meses. Dessa forma, nessas salas de aula, as interações discursivas entre seus membros, ao longo do tempo e dos eventos, favoreceram a maior interação entre os(as) estudantes.

Ao analisarmos mais detalhadamente essas interações discursivas das aulas sobre Mutualismo e Sistema Nervoso, podemos observar que os(as) estudantes também 
influenciaram-se e direcionaram o discurso. $\mathrm{Na}$ aula sobre Mutualismo (Figura 10), por exemplo, a informação do livro, trazida por Marcelo (L257) direcionou a discussão e foi utilizada como ponto de partida para a construção do argumento das colegas Érica (L265) e Gabriela (L270), que começaram a levantar hipóteses sobre a relação crocodilo, sanguessuga e pássaro-palito. Essa ação do aluno Marcelo também estimulou a participação de Alessandra (L273), que trouxe um exemplo em que excesso de sanguessugas foi prejudicial para outro animal e talvez também pudesse ser prejudicial para o crocodilo.

Figura 10. Trecho da transcrição da aula sobre Mutualismo - turma EJA

\begin{tabular}{|c|c|}
\hline 256 & $\begin{array}{l}\text { Professor: Esse parece mais com esse aí / pois eles estão juntos / porque não tem uma } \\
\text { obrigatoriedade / o crocodilo consegue viver lá / se o pássaro não existir / }\end{array}$ \\
\hline 257 & $\begin{array}{l}\text { Marcelo: Mas aqui / o negócio é o seguinte / Dentro da garganta do crocodilo também ficam } \\
\text { alojadas sanguessugas / não é? / }\end{array}$ \\
\hline 258 & Professor: É? / Ele pega também sanguessuga? / \\
\hline 259 & $\begin{array}{l}\text { Marcelo: Ele fica tirando elas da garganta do crocodilo / um ajuda o outro também / não é? / O } \\
\text { pássaro se alimenta e ajuda o crocodilo tirando as sanguessugas lá / }\end{array}$ \\
\hline 260 & Professor: Pois é / \\
\hline 261 & Marcelo: (Inaudível) nem vai por causa da carne do peixe / é questão da sanguessuga / \\
\hline 262 & Professor: Isso da sanguessuga eu não sabia / eu sabia que ele pegava carne / \\
\hline 263 & Marcelo: A carne não / a carne é da sanguessuga que eu falei / \\
\hline 264 & Professor: Então / \\
\hline 265 & Érica: Mas não tem jeito do crocodilo engolir a sanguessuga não? / \\
\hline 266 & $\begin{array}{l}\text { Marcelo: Pelo que eu li no livro / eu não sei se o livro estava mentindo ou não / mas pelo que } \\
\text { eu li lá / é que as sanguessuga fica na garganta do crocodilo / (fala olhando para o professor) }\end{array}$ \\
\hline 267 & $\begin{array}{l}\text { Professor: Mas se / por exemplo / tiver o pássaro-palito / e no lugar que ele está vivendo não } \\
\text { tem crocodilo / será que ele morre / ou será que ele consegue outra forma de alimento? / Eu } \\
\text { também acho que consegue / Então / mutualismo é quando é obrigatório / Um exemplo de } \\
\text { mutualismo / }\end{array}$ \\
\hline 268 & Gabriela: O pássaro-palito consegue outros alimentos / \\
\hline 269 & Professor: Consegue / acho que consegue / \\
\hline 270 & $\begin{array}{l}\text { Gabriela: O crocodilo pode ser que seja para ele um alívio / esse pássaro fazer uma limpeza na } \\
\text { garganta dele / }\end{array}$ \\
\hline 271 & $\begin{array}{l}\text { Professor: É um alivio / mas assim / não é uma coisa obrigatória / Se não tiver o pássaro-palito } \\
\text { / o sanguessuga vai matar ele? / }\end{array}$ \\
\hline 272 & alunos: Inaudível (muitos falam ao mesmo tempo) \\
\hline 273 & $\begin{array}{l}\text { Professor: Não / mas o sanguessuga / o crocodilo também tem as defesas dele para expulsar os } \\
\text { sanguessugas / produz um ácido / alguma coisa ali / eu não sei / estou pensando aqui / Âs vezes } \\
\text { / vai causar um prejuízo para ele / mas não vai chegar / só se tiver muito mesmo pra matar ele / }\end{array}$ \\
\hline 274 & $\begin{array}{l}\text { aluna: (difícil de discernir, mas parece que ela conta um caso falando de gado morrendo por } \\
\text { causa de sanguessuga no córrego) }\end{array}$ \\
\hline 275 & Professor: Se tiver muito / aí é perigoso / \\
\hline
\end{tabular}


Além de servir de recurso para o discurso dos(as) colegas, podemos observar que a informação sobre a sanguessuga trazida por Marcelo também contribuiu para o discurso do professor, que agiu como antagonista por meio de questões. Primeiro, Domingos questionou Marcelo, buscando mais esclarecimento sobre a informação (L258). Depois, ele desafiou a validade dessa informação em dois momentos. Primeiro, no sentido de que, para ser Mutualismo, é necessário que a relação seja obrigatória tanto para crocodilo quanto para pássaro-palito (L267). Segundo, no sentido de verificar se essa informação de fato é obrigatória a ponto de causar a morte do crocodilo na ausência do pássaro-palito (L271 e L273).

Nas interações da aula sobre Sistema Nervoso (Figura 11), também podemos observar como os(as) estudantes usaram informações do texto como recurso e influenciaram uns aos outros e a professora. Iago consultou o texto que a turma leu antes do desacordo (L167). A professora valorizou o fato do aluno utilizar esse recurso e solicitou que ele apresente mais elementos para estruturar seu argumento (L168 e L170). Pedro apresentou um contra-argumento ao posicionamento de que o formato com quinas é mais seguro (L173). Entretanto, a professora perguntou se os colegas o ouviram (L176), sugerindo a importância de ouvir o colega para participar da discussão. A professora pediu para ele repetir (L178), valorizando a opinião do aluno. O contraargumento de Pedro (L179) foi utilizado como base de raciocínio de Joana (L185), que foi convidada pela professora a se posicionar (L180). Esse raciocínio de Joana foi contraposto por Iago (L186), que apoiou Pedro. Entretanto, antes de Joana apresentar seu raciocínio, a professora formulou o posicionamento da aluna para a turma, agiu como antagonista, desafiando a validade desse posicionamento ao se referir à necessidade de "sorte de cair reto" e convidou os outros estudantes a participarem da discussão (L183).

Em síntese, podemos dizer que não houve variações significativas, ao longo do tempo, em relação às ações e posicionamentos dos professores. Por outro lado, em relação aos(às) estudantes, essa variação foi significativa. Nas duas turmas, apesar de os(as) estudantes sempre responderem aos questionamentos dos professores, depois de mais tempo de convivência, eles(as) também interagiram mais com os pares, direcionando o discurso e influenciando-se mutuamente e aos professores. Além disso, utilizaram livro/ texto como recurso para construir argumentos e se posicionaram como antagonistas, apresentando contra-posições explicitamente.

Apesar de não ter sido possível exemplificar todas as ações e formas de posicionamento de cada professor, observamos semelhanças e diferenças nas duas turmas. Ambos se posicionaram predominantemente por meio de questões, o que possibilitou manter seu posicionamento como protagonista implícito durante muito tempo ao longo da interação. Ao mesmo tempo, essas questões representaram o posicionamento de antagonista e tiveram diferentes funções. Assim, ambos questionaram os(as) estudantes para solicitar mais elementos, fornecer esclarecimentos e desafiar a validade da informação trazida pelo(a) estudante. 
Figura 11. Trecho da transcrição da aula sobre Sistema Nervoso - turma $8^{\circ}$ ano

\begin{tabular}{|c|c|}
\hline 167 & $\begin{array}{l}\text { Iago: Eu acho que o redondo seria melhor / Eu acho que nesse sentido / (fala conferindo } \\
\text { informações no caderno) / as meninges / elas deixam o cérebro (inaudível) / }\end{array}$ \\
\hline 168 & $\begin{array}{l}\text { Professora: o Iago foi muito esperto / Ele foi buscar elementos na própria folha / para dizer que } \\
\text { mesmo que / se tivesse essa diferença de formato / o cérebro tem o que? / O que você achou } \\
\text { aí? / }\end{array}$ \\
\hline 169 & Iago: as meninges / \\
\hline 170 & Professora: as meninges que iam o que? / \\
\hline 171 & Iago: iam deixar ele parado / \\
\hline 172 & $\begin{array}{l}\text { Professora: parado / estabilizado / Então / tem isso / porque elas também são para proteção / } \\
\text { Pedro / pode falar / }\end{array}$ \\
\hline 173 & $\begin{array}{l}\text { Pedro: Eu acho que se fosse quadrada / mesmo se estivesse certinho [o cérebro] / quando caísse } \\
\text { / se batesse as quinas / ia poder machucar / }\end{array}$ \\
\hline 174 & Professora: o que você falou? / (pergunta olhando para Fabrício) \\
\hline 175 & Fabrício: estou concordando com ele / \\
\hline 176 & Professora: está concordando / Vocês ouviram o que o Pedro disse? / \\
\hline 177 & Mário: Não / \\
\hline 178 & Professora: Pedro / repete mais alto / por favor / \\
\hline 179 & $\begin{array}{l}\text { Pedro: Porque se fosse um quadrado certinho / quando caísse / as quinas poderia machucar a } \\
\text { pessoa / }\end{array}$ \\
\hline 180 & Professora: Pois é / Joana / e aí? / \\
\hline 181 & Joana: Não podia ou podia? / \\
\hline 182 & os alunos respondem juntos: Podia / \\
\hline 183 & $\begin{array}{l}\text { Professora: Podia / poderia / Porque a Joana ficou falando uma coisa / que se a gente caísse ia } \\
\text { reto / mas tinha que dar a sorte de cair sempre reto / sempre com uma face para o solo / Mas e } \\
\text { se a gente caísse ou esbarrasse de ponta / O que vocês acham? / }\end{array}$ \\
\hline 184 & Muitos alunos falam ao mesmo tempo. É possível ouvir: “ia amassar" "ia quebrar" \\
\hline 185 & $\begin{array}{l}\text { Joana: eu mudei um pouco minha opinião / Não ia fazer diferença se fosse redonda ou quadrada } \\
\text { / porque se a gente vai ter essa parte quadrada ou a quina / só ia (inaudível) / e se a gente bater } \\
\text { o redondo aqui / também morre / Então / não tem diferença / Vai morrer de qualquer jeito / }\end{array}$ \\
\hline 186 & Iago: mas o quadrado é mais fraco / Ele tem mais pontas (inaudível) / \\
\hline
\end{tabular}

Quanto às diferenças, observamos que, além dessas ações, a professora Beatriz explicitava em todas as aulas a importância de ouvir o colega para participar da discussão, formulava os posicionamentos e argumentos dos(as) estudantes para a turma e convidavaos(as) a se posicionar. Além disso, quando a professora se posicionou explicitamente, o desacordo foi encerrado. Situação similar aconteceu ao professor Domingos somente na aula sobre Sistema ABO. Nas aulas sobre Resíduos sólidos e Mutualismo, por outro lado, quando o professor se posicionou explicitamente as diferenças de opinião continuaram.

Além dessas diferenças entre as turmas, observamos, ao analisar e cruzar todo o conjunto de dados, variações nos processos argumentativos considerando-se a mesma turma. Na turma da EJA, o processo de cada aula teve uma especificidade. Na aula sobre Sistema $\mathrm{ABO}$, ao interagirem discursivamente, professor e estudantes geraram novos 
desacordos mais específicos para resolver o desacordo principal. Na aula sobre Resíduos sólidos, o processo de resolução envolveu o desacordo sobre duas proposições: medir material ou objetos; e usar padrão de medida convencional ou criar um padrão de medida para a turma. $\mathrm{Na}$ aula sobre Mutualismo, por outro lado, a maior participação dos(as) estudantes possibilitou que, no processo de resolução dos desacordos, houvesse mais contra-posições e os posicionamentos fossem sustentados por mais argumentos.

$\mathrm{Na}$ turma do $8^{\circ}$ ano, os processos argumentativos também tiveram suas especificidades. Na aula sobre Sistema Excretor, os questionamentos da professora ajudou a explicitar e a reestruturar o posicionamento e o argumento defendido pelos(as) estudantes. Esses questionamentos também estabeleceram implicitamente algumas regras para a argumentação, que a professora utilizou como referência para se contrapor aos(às) estudantes. Na aula sobre Sistema Nervoso, por outro lado, a maior interação dos(as) estudantes com os pares, contribuiu para que, no processo de resolução dos desacordos, houvesse mais contra-posições e os posicionamentos fossem sustentados por mais argumentos. Nesse processo, a professora apresentou as regras de argumentação explicitamente e, ao explicitar seu posicionamento e argumentos, sintetizou as contribuições dos(as) estudantes.

\section{Discussão}

Nessa seção, buscamos responder à questão: Como processos argumentativos das duas turmas estão relacionados à construção de uma cultura de sala de aula favorável à argumentação? Para a construção de resposta a essa questão, consideramos os vários aspectos relacionados à construção de uma cultura da argumentação discutidos mais no início do artigo.

Com relação ao primeiro aspecto, observamos que, o conhecimento científico esteve sujeito à dúvida e incerteza (Henderson et al., 2018), apesar de as situações em que ocorreram argumentação terem sido predominantemente aquelas em que se discutiram aspectos bastante conceituais, sem muita margem para variação de posição, sob a perspectiva da Educação em Ciências. Isso se deu principalmente devido às ações de questionamento dos professores, que resultaram no surgimento e no processo de resolução de desacordos.

Dessa forma, diferentemente do estudo de Sandoval e colaboradores (2019), os desacordos não surgiram a partir de discordâncias naturais entre os(as) estudantes, mas a partir de intervenções de Domingos e Beatriz, que valorizavam o diálogo e os conhecimentos dos(as) estudantes como essenciais no processo de construção de conhecimento científico em sala de aula. Esses questionamentos também contribuíram para tornar visível a tensão entre os conhecimentos científicos e os dos(as) estudantes (El-Hani e Mortimer (2007), criando um ambiente seguro para que os(as) estudantes manifestassem seus posicionamentos e argumentos (Henderson et al., 2018).

O segundo aspecto da cultura favorável à argumentação corresponde à crítica e à avaliação. Isso se deu por meio de interações em que alguém assumiu o papel de antagonista, ou seja, de não se alinhar às posições apresentadas, seja do texto, seja de um(a) 
estudante, ou do(a) próprio(a) professor(a), no caso do estudante. Esse antagonismo foi construído de forma implícita ou explícita, sendo que quando o(a) professor(a) assumiu um papel de antagonista isso foi feito principalmente por meio de questões. Tais questões referiram-se a pensar em outras situações, trazer novas informações ou dados sobre a situação analisada, solicitar que os(as) estudantes apresentassem mais informações sobre suas afirmações.

Os(as) estudantes, por outro lado, posicionaram-se explicitamente como antagonistas, apresentando objeções a posicionamentos e argumentos (Leitão, 2000), principalmente quando interagiram mais com seus pares. Essas interações envolveram avaliação de evidências e do raciocínio que os colegas apresentam, que segundo González-Howard e McNeill (2020) são interações dialógicas que favorecem crítica e a avaliação. Além disso, as críticas foram direcionadas às ideias, não a pessoas (Henderson et al., 2018). Por exemplo, observamos que quando um(a) estudante contrapôs a fala de outro(a) colega, foi considerado o conteúdo apresentado nessa fala, sem influências significativas das relações pessoais que tinham entre si, ou seja, não importava se eles(as) tinham afinidade ou não com quem falou, mas se concordavam ou não com a ideia apresentada.

Com relação ao terceiro aspecto de uma cultura favorável à argumentação, dimensão temporal e processual, observamos, por exemplo, que as formas de interação dos(as) estudantes entre pares ocorreram de forma mais significativa depois de meses de convivência entre os membros do grupo. Esses resultados corroboram a noção de que normas e expectativas são construídas discursivamente ao longo do tempo e dos eventos (ver por exemplo Dixon \& Green, 2005; Green et al., 2005; McDonald \& Kelly, 2012).

Dessa forma, esses resultados também contribuem para explicar como mudanças nas práticas das comunidades de sala de aula não são triviais (Berland \& Reiser, 2011), pois demandam ações não pontuais, principalmente, dos(as) docentes. Além disso, esses resultados são coerentes com a dimensão processual (Larraín \& Freire, 2011). Assim como no estudo dessas autoras, nas duas turmas, o foco não era compreender a estrutura de argumentos, mas criar condições para que estudantes fossem estimulados(as) a defender seus pontos de vista e a apresentar críticas às ideias opostas.

O quarto aspecto de uma cultura favorável à argumentação está relacionado à diversidade. $\mathrm{O}$ contraste entre os eventos das aulas das duas turmas trouxe muitas evidências de que os processos argumentativos variam na mesma turma ao longo do tempo e dos eventos e em diferentes turmas. Esses resultados corroboram os resultados de Berland e Reiser (2011), não em relação aos objetivos de persuasão e sense-making analisados por esses autores, mas no sentido de que existe variação nas formas de engajamento dos(as) estudantes em diferentes turmas que resultam em diferentes formas de argumentar.

Assim como no estudo de Baker (2015), observamos que a consideração de conflitos não declarados, como dúvidas e questões, aumenta as possibilidades e a variedade de argumentação. Nos contextos que investigamos, por exemplo, os desacordos surgiram e foram resolvidos principalmente por meio de questões e foram 
muito diversos. Dessa forma, podemos dizer que outras formas de argumentar e criticar foram reconhecidas na comunidade de sala de aula, além das formas dominantes de conhecer e explicar o mundo, como sugerido por Gonzálex-Howard e McNeill (2020). Esse reconhecimento pode contribuir para a inclusão de grupos minoritários, como por exemplo, os(as) estudantes jovens e adultos.

Com relação ao quinto e último aspecto de uma cultura favorável à argumentação, dimensão social e coletiva, observamos que as ações e comunicação de docentes e estudantes são moldadas pelas respostas (verbais ou não verbais) de outros membros da sala de aula (Dixon \& Green, 2005). Por exemplo, evidencia-se como a informação de um livro, trazida por um colega pode direcionar o discurso da turma, fazendo com que outros(as) estudantes se engajem na discussão de um exemplo, contribuindo para a resolução do desacordo e levando colegas a mudarem de ideia à medida que interagem com seus pares. Além disso, essa informação também moldou as ações do professor que solicitou esclarecimentos e desafiou a validade dessa informação. Esses resultados corroboram os encontrados por Rudsberg et al. (2017), que apresentam evidências de que os estudantes influenciam o raciocínio de outros estudantes.

Outro aspecto que observamos é que algumas ações dos professores pareceram similares às ações favoráveis à argumentação de instrumentos de análises de outros estudos como os de Ferraz e Sasseron (2017), Ibraim e Justi (2018) e Larraín e Freire (2011). Por exemplo, houve situações em que os professores questionaram as respostas dos(as) estudantes no sentido similar ao que Ferraz e Sasseron (2017) classificaram como Explorar; ao que Larraín e Freire (2011) classificaram como "Deter-se ao que é dito pelo aluno para aprofundar e entender seu ponto de vista"; e ao que Ibraim e Justi (2018) classificaram como "Encorajar o(s) aluno(s) a apresentar(em) justificativa(s) para sua(s) afirmação(ões)".

Essas classificações, apesar de relacionadas a instrumentos analíticos diferentes, têm em comum o fato de o(a) professor(a) ter como objetivo fazer com que os estudantes esclareçam ou tragam mais elementos aos seus pontos de vista ou argumentos. Entretanto, as ações dos professores não foram sempre as mesmas contrastando os dois contextos, nem mesmo quando consideramos a mesma turma.

Observamos, portanto, que as ações dos(as) professores(as) não teriam favorecido a argumentação, se os(as) estudantes não fossem positivamente responsivos(as) a elas. Esse resultado corrobora a compreensão de que as ações de professores(as) e estudantes são indissociáveis e estão diretamente relacionadas aos contextos que permeiam cada sala de aula (Ferraz \& Sasseron, 2017).

\section{Considerações finais}

As análises dos contrastes dos processos argumentativos da turma da EJA e do $8^{\circ}$ ano do ensino regular, a partir das características de uma cultura de sala de aula favorável à argumentação, nos permite afirmar que ambas as turmas apresentam características desse tipo de cultura, mesmo em contextos com características aparentemente 
desfavoráveis à argumentação. Nossos resultados evidenciam que as formas de interação e a responsividade do(a) professor(a) às características da turma, podem ter sido fundamentais para a construção desse tipo de cultura de sala de aula.

Dessa forma, não queremos minimizar o papel que contextos, como por exemplo os de investigação e os que envolvem questões sociocientíficas, têm para a construção dessa cultura. Nossas análises sugerem, porém, que a construção dessa cultura não se restringe a contextos como estes e também pode ocorrer de diversas formas, desde que haja valorização do diálogo e dos conhecimentos dos(as) estudantes como essenciais no processo de construção de conhecimento científico em sala de aula. Assim, é fundamental desafiar-se perspectivas de déficit sobre a prática docente e as salas de aula da Educação Básica, como se a argumentação fosse algo totalmente "estranho" aos aspectos da cultura de salas de aula já instauradas.

Nossos resultados evidenciam também o potencial de estudos mais descritivos para caracterizar a argumentação em salas de aula de Ciências. A partir de descrições e análises mais aprofundadas das interações discursivas de cada sala de aula, tendo como fundamentação teórico-metodológica a Etnografia em Educação e a Pragma-dialética, foi possível dar visibilidade à diversidade de processos argumentativos que contribuem para a construção de uma cultura favorável à argumentação. Para ampliarmos nosso conhecimento sobre essa diversidade, recomendamos mais estudos descritivos, que analisem as ações dos(as) professores(as) de forma articulada com as ações e reações dos(as) estudantes, que envolvam mais tempo em campo para a coleta de dados e que investiguem contextos instrucionais diversos.

Além das contribuições para o campo de pesquisa, o presente estudo apresenta implicações para as práticas pedagógicas dos professores, pois traz elementos que evidenciam como as formas de interação entre professores(as) e estudantes criam possibilidades de argumentação mesmo em contextos instrucionais considerados mais tradicionais, como aulas expositivas-dialogadas e correção de exercícios. Esse conhecimento pode orientar cursos e disciplinas de formação de professores.

\section{Agradecimentos}

Agradecemos ao financiamento da CAPES pela bolsa de PNPD - que oportunizou o processo de aprimoramento da abordagem teórico-metodológica alternativa para o estudo da argumentação que propõe aproximações entre a Etnografia em Educação e a Pragma-dialética e uma maior compreensão sobre as características de uma cultura de sala de aula favorável à argumentação - e pela bolsa de doutorado, que possibilitou a coleta e análise de dados na turma do $8^{\circ}$ ano do Ensino Fundamental regular e a proposição de uma abordagem teórico-metodológica alternativa para o estudo de argumentação em salas de aula de Ciências. Agradecemos também ao CNPq pelos recursos financeiros do Edital Ciência na Escola, bolsa produtividade e bolsa de mestrado, a qual proporcionou a coleta e análise de dados na turma da Educação de Jovens e Adultos e a primeira aproximação entre Etnografia em Educação e a teoria da argumentação Pragma-dialética. 


\section{Referências}

Baker, M. J. (2015). The integration of pragma-dialectics and collaborative learning research: dialogue, externalisation and collective thinking. In F. A. van Eemeren, \& B. Garssen (Eds.) Argumentation in Context, 175-199. Amsterdam: John Benjamins Publishers.

Berland, L. K., \& Hammer, D. (2012). Framing for Scientific Argumentation. Journal of Research In Science Teaching. 49(1), 68-94.

Berland, L. K., \& Reiser, B. J. (2011). Classroom communities' adaptations of the practice of scientific argumentation. Science Education, 95(2), 191-216.

Billig, M. (1987) The art of witcraft. In M. Billig. Arguing and thinking: A rhetorical approach to social psychology (82-117). Cambridge University Press.

Bloome, D., Carter, S. P., Christian, B. M., Otto, S., \& Shuart-Faris, N. (2005) Discourse Analysis and the study of classroom language and Literacy Events: a Microethnografic perspetive. Lawrence Erlbaum Associates.

Castanheira, M. L., Green, J. L., \& Dixon, C. N. (2007) Práticas de letramento em sala de aula: uma análise de ações letradas como construção social. Revista Portuguesa de Educação, 20(2), 7-38.

Dixon, C., \& Green, J. (2005). Studying the Discursive Constructions of Texts in Classrooms Through Interactional Ethnography. In R. Beach, J. Green, M. Kamil, \& T. Shanahan (Eds.), Multidisciplinary Perspectives on Literacy Research (2 ed.). Santa Barbara: Hampton Press Cresskill.

Duschl, R. (2008). Science Education in Three-Part Harmony: Balancing Conceptual, Epistemic, and Social Learning Goals. Review of research in Education, 32(1), 268-291.

EL-Hani, C. N. \& Mortimer, E. F. (2007). Multicultural Education, Pragmatism, and the Goals of Science Teaching. Cultural Studies of Science Education, 2(3), 657-687.

Ferraz, A. T., \& Sasseron, L. H. (2017). Propósitos epistêmicos para a promoção da argumentação em aulas investigativas. Investigações em Ensino de Ciências, 22(1), 42-60.

González-Howard M, McNeill KL. (2020). Acting with epistemic agency: Characterizing student critique during argumentation discussions. Science Education. 1-30. https://doi. org/10.1002/sce.21592

Green, J., Dixon, C., \& Zaharlick, A. (2005) A etnografia como uma lógica de investigação. Educação em Revista, 42, 13-79.

Henderson, J. B., McNeill, K. L., González-Howard, M., Close, K., \& Evans, M. (2018). Key Challenges and Future Directions for Educational Research on Scientific Argumentation. Journal of Research in Science Teaching, 55(1), 5-18. 
Ibraim, S. de S., \& Justi, R. (2018). Ações docentes favoráveis ao ensino envolvendo argumentação: estuda da prática de uma professora de química. Investigações em Ensino de Ciências, 23(2), 311-330.

Jiménez-Aleixandre, M. P. \& Erduran, S. (2007). Argumentation in Science Education: An Overview. In M. P. Jiménez-Aleixandre, \& S. Erduran. Argumentation in Science Education: perspectives from classroom-based research (03-25). Springer.

Kelly, G. J. (2005) Discourse, description, and science education. In R. Yerrick, W. M. Roth (eds), Establishing Scientific Classroom Discourse Communities: Multiple Voices of Research on Teaching and Learning (79-108). Mahwah, NJ: Lawrence Erlbaum.

Larrín, A. \& Freire, P. (2011). Capitalizando a controvérsia: algumas reflexões para tornar visível e aproveitar a contra-argumentação dos alunos no Ensino de Ciências. In S. Leitão, \& M. C. Damianovic (Orgs.), Argumentação na escola: o conhecimento em construção (47-80). Campinas, SP: Pontes Editores.

Leitão, S. (2000). The potential of argument in knowledge building. Human development. 43(6), 332-360.

Lincoln, Y. S., \& Guba, E. G. (1985) Naturalistic inquiry. Sage Publications, Inc.

McDonald, S. P., \& Kelly, G. J. (2012) Beyond Argumentation: Sense-Making Discourse in the Science Classroom. In M. S. Khine (ed) Perspectives on Scientific Argumentation: Theory, Practice and Research (265-281). Springer.

McNeill, K. L., \& Pimentel, D. S. (2010) Scientific discourse in three urban classrooms: The role of the teacher in engaging high school students in argumentation. Science Education, 94(2), 203-229.

Munford, D., \& Teles, A. P. S. S. (2013). Argumentação e construção de oportunidades de aprendizagem em aulas de Ciências sobre Corpo Humano em uma turma do $8^{\circ}$ ano do ensino fundamental. In IX ENPEC - Encontro Nacional em Pesquisa em Educação em Ciências, Águas de Lindóia. Atas do IX Encontro Nacional de Pesquisa em Educação em Ciências IX ENPEC, 1-8.

Munford, D., \& Teles, A. P. S. S. (2015). Argumentação e a construção de oportunidades de aprendizagem em aulas de Ciências. Ensaio: Pesquisa em Educação em Ciências, 17, 161-185.

Rex, L. A. (2006). Introduction. In L. A. Rex (ed.) Discourse of opportunity: How talk in learning situations creates and constrains (1-35). Hampton Press Inc.

Rudsberg, K., Östman, Leif. \& Östman, Elisabeth. A. (2017) Students' meaning making in classroom discussions: the importance of peer interaction. Cultural Studies of Science Education 12, 709-738. https://doi.org/10.1007/s11422-015-9721-5

Sandoval, W. A., Enyedy, N., Redman, E. H. \& Xiao, S. (2019): Organising a culture of argumentation in elementary science. International Journal of Science Education, 4, 1848-1869. https://doi.org/10.1080/09500693.2019.1641856 
Schwarz, B. B. (2009) Argumentation and Learning. In N. M. Mirza, \& A. N. P. Clermont (eds), Argumentation and Education: Theoretical Foundations and Practices (91-126). London, Springer.

Skukauskaité, S., Liu, Y., \& Green, J. L. (2007). Editorial Introduction: Logics of Inquiry for the Analysis of Video Artefacts: Researching the Construction of Disciplinary Knowledge in Classrooms. Pedagogies: an International Journal. 2(3), 131-137.

Spradley, J. (1980) Participant observation. Holt, Rinehart; Winston.

Stake, R. E. (1998). Case Studies. In N. K. Denzin, \& Y. S. Lincoln. Strategies of Qualitative Inquiry (86-109). Thousand Oaks, SAGE Publications.

van Eemeren F. H., Grootendorst, R. (2004) A Systematic Theory of Argumentation: The pragma-dialectical approach. Cambridge University Press.

van Eemeren, F. H., Grootendorst., R., \& Henkemans, A. F. S. (2002). Argumentation: Analysis, Evaluation, Presentation. New Jersey, Lawrence Erlbaum Associates.

\author{
Ana Paula Souto Silva Teles \\ Universidade Federal de Minas Gerais \\ Faculdade de Educação \\ Belo Horizonte, Minas Gerais, Brasil \\ anapaulasoutos@gmail.com
Danusa Munford
Universidade Federal do $A B C$ Centro de Ciências Naturais e Humanas
Santo André, São Paulo, Brasil
danusa.munford@ufabc.edu.br

Editora Responsável

Marta Maximo

Manifestação de Atenção às Boas Práticas Científicas e de Isenção de Interesse

Os autores declaram ter cuidado de aspectos éticos ao longo do desenvolvimento da pesquisa e não ter qualquer interesse concorrente ou relações pessoais que possam ter influenciado o trabalho relatado no texto. 